\title{
Dimensiones de la confección de una juventud virtuosa: manuales de urbanidad en Chile (c.1840-c.1900) ${ }^{1}$
}

\author{
Pablo Toro Blanco $(*)$
}

\begin{abstract}
RESUMEN
Se ha señalado que la idea de juventud es una construcción social y cultural, condicionada por su entorno y contingencia. Así, la historiografía ha coincidido en notar la escolarización como uno de sus factores más destacados. En este texto se busca analizar una dimensión específica de cómo se confeccionó la moderna noción de juventud en Chile durante la segunda mitad del siglo XIX. Se sostiene que a través del estudio de contenidos presentes en los manuales de urbanidad que circularon en la enseñanza secundaria pública en esa época es posible observar elementos constitutivos del discurso normativo respecto a cómo debía ser la juventud formada en las aulas del sistema educacional en consolidación.
\end{abstract}

Palabras clave:

Juventud chilena - urbanidad - manuales escolares.

\footnotetext{
(*) Doctor en Historia de la Pontificia Universidad Católica de Chile. Académico del Departamento de Historia de la Universidad Alberto Hurtado.

Artículo enviado el 14 de septiembre de 2011. Aceptado por el Comité Editorial el 14 de mayo de 2012.

Correo electrónico: ptoro@uahurtado.cl.

${ }^{1}$ Este artículo se enmarca en el desarrollo del Proyecto Fondecyt 11090036. "Definiendo a una juventud: Liceos, textos escolares, opinión pública en la definición del sujeto juvenil en Chile c.1870-c.1920", del cual el autor es investigador responsable.
} 


\begin{abstract}
It has been pointed out that the idea of youth is a social and cultural construction determined by his environment and circumstances. Historiography has coincided in considering the schooling process as one of his most important factors. This paper analyzesa specific dimension of how the modern notion of youth was handcrafted in Chile during the second half of the XIXth century. In a reading of theetiquette handbooks used in the public secondary education it is possible to observe constitutive elements of the normative speech with regard to how the youth has to be formed in the classrooms of the educational system in consolidation.
\end{abstract}

Keywords:

Chilean youth - urbanity - school manuals.

\title{
Presentación
}

A través del siglo XIX hubo en Chile una amplia gama de iniciativas de fomento a la expansión de la educación escolar como vehículo modernizador, racionalizador y constructor de legitimidad republicana. En términos generales, es posible señalar que el sistema educacional se desarrolló de acuerdo a una lógica dual: por una parte, una red de instrucción primaria orientada hacia la moralización y capacitación básica de los grupos populares y de otro lado, con un peso simbólico muy relevante desde los inicios del proceso independentista, una enseñanza colegial o secundaria, principalmente masculina, que estaba pensada como un crisol en el que se forjarían los grupos dirigentes republicanos, los que serían generados desde una atención exclusiva a los méritos individuales de los jóvenes estudiantes en desmedro del peso del prestigio familiar o corporativo heredado por la tradición, factor asociado al orden colonial que se buscaba dejar atrás ${ }^{2}$. Así, de manera no siempre coordinada aunque invariablemente tendiente a prácticas y discursos centralizadores, fue surgiendo a través del siglo una red de liceos públicos y colegios secundarios privados orientados a la atención y formación de la juventud chilena.

Tomando los recaudos necesarios respecto a las diferencias de su proceso en relación a los que se experimentaban en la Europa atlántica (los que, por lo demás, las elites republicanas en el país y en Latinoamérica en general aspiraban a reproducir), es posible considerar al mecanismo de escolarización recién señalado como uno de los factores coadyuvantes en el inicio del camino hacia la constitución en Chile de la moderna concepción social de juventud como una etapa vital dotada de ciertas peculiaridades, un tramo de la existencia con atributos propios y con posibilidades de construir una identidad como colectivo, asignada desde afuera y asumida y vivida desde adentro. Es posible plantear que, en términos globales, el espacio de reconocimiento social de la juventud ha operado su expansión siguiendo patrones que se difunden desde los grupos altos y medios hacia los populares, desde el medio

\footnotetext{
${ }^{2}$ Respecto a la idea de escasa integración del sistema escolar decimonónico, la referencia más frecuente es lo sostenido por Amanda Labarca, Historia de la enseñanza en Chile, Ediciones de la Universidad de Chile, Santiago, 1939, p. 359 y ss.
} 
cultural urbano hacia el ámbito de lo rural y que se ha construido desde un criterio de segregación de género, en el que los atributos modernos de lo juvenil como rasgo de construcción de identidad han sido distinguidos primero en los hombres y luego en las mujeres ${ }^{3}$.

En ese escenario, formas tales como las que adoptó el sistema escolar secundario chileno son congruentes con el patrón general expuesto, en la medida que compartieron similares propósitos de transferencia de espacios formativos desde el ámbito de lo familiar a la esfera de lo público, en tanto lo escolar se constituyó en un lugar de materialización de los esfuerzos racionalizadores y normalizadores, un sitio de calificación de un segmento de la población que fue congregado para ser moldeado en valores republicanos y de adscripción a una imago mundi europeizante. A través de un proceso de adaptación de elementos de un flujo transcontinental de circulación de ideas sobre la formación de la infancia y la juventud se engendró, para el caso chileno, una versión predominantemente secularizada de tales preceptos, aunque no resultó ser un producto totalmente desprendido de la tradicional matriz cultural de cuño religioso.

De acuerdo a lo anterior es que el proceso se nos aparece como un acto de confección, en la medida que si bien obedece a moldes que le dan forma y le sirven de referencia, sin embargo es a la vez una combinación contingente de los elementos disponibles, que se adapta en sus medidas al cuerpo social y cultural de un país que experimenta procesos no necesariamente alineados a los de aquellos que son considerados modelos a seguir. En tal sentido, deseamos apartarnos de las comprensiones de los procesos históricos que le niegan agencia a individuos, actores sociales e instituciones al someterlos a una suerte de rígida gramática del poder que diluye su historicidad. En definitiva, desearíamos relativizar las lecturas más ortodoxamente foucaltianas (si es que este término puede tener algún sentido $)^{4}$.

Es en medio del proceso recién señalado que se concentra el interés de estas páginas. A través de un campo específico, la presencia en el sistema escolar de referencias a la urbanidad como un campo normativo que debía ser promovido por los colegios formadores de una juventud virtuosa, se pretende apreciar algunos ribetes del proceso de construcción del discurso sobre lo juvenil en el Chile de mediados del siglo XIX hasta el fin de la época decimonónica. Intentamos distinguir algunos leves matices entre una propuesta de urbanidad derivada principalmente de consideraciones morales con sólida base religiosa y frente a ella, pero no completamente en sus antípodas, una noción de urbanidad más bien tributaria de una idea secular y racional respecto a la sociedad. Si bien los elementos que separarían a ambas perspectivas podrían estar engarzados con la disputa global entre una visión de cristiandad y un enfoque laicista de la legitimación del orden republicano, no habrían disensos importantes en

\footnotetext{
${ }^{3}$ Sandra Souto Kustrin, "Introducción: juventud e historia". En Hispania. Revista Española de Historia, 2007, vol. LXVII núm. 225 , enero-abril, p.13.

${ }^{4}$ Sobre la necesidad de integrar de manera razonada los valiosos aportes de Foucault sin absolutizar su noción de poder y con ello hacer desaparecer la capacidad de los actores históricos, aplicado al caso de la constitución de lo juvenil, ver Rodney Hessinger, Seduced, abandoned and reborn. Visions of Youth in middle-class America, 1780-1850, University of Pennsylvania Press, Philadelphia, 2005, p.15.
} 
un punto estratégico: asegurar que se lograra trasmitir, paralelamente a la formación intelectual de los jóvenes estudiantes, ciertos códigos conductuales que permitieran su normalización en términos de aspecto, lenguaje y corporalidad, que aseguraran la tutoría adulta y que internalizaran en los muchachos control sobre sus actos en el dominio público.

Para cumplir con nuestro propósito se ha delimitado como objeto de estudio un corpus de manuales y catecismos, que sirvieron como referencias normativas para apoyar los esfuerzos de los docentes por transmitir a sus estudiantes códigos conductuales y estilos de disposición de palabras, miradas y gestos comme il faut. Una primera operación que se aborda es caracterizar brevemente el tipo de textos que se analizan, contextualizándolos al interior del desarrollo de la cultura impresa chilena de la época en estudio. Complementariamente, se presenta una perspectiva sumaria acerca del espacio curricular y las prácticas docentes en las cuales estos textos pudieron tener algún tipo de impacto en la formación de los jóvenes. Finalmente, se recogen conceptos de urbanidad presentes en los textos, intentando precisar elementos, específicamente aquellos relacionados con las conductas en los espacios públicos, que sirvan para elaborar una breve reflexión sobre la formación de la juventud entendida como una confección.

\section{Manuales y catecismos al interior del mundo escrito chileno en el siglo XIX chileno}

Para poder componer una perspectiva general apropiada sobre los textos que se analizan en estas páginas, resulta imprescindible situarlos sumariamente en el entorno de la industria editorial chilena de la época. Sin ánimo de explorar los riesgos de un camino profundamente incierto (el de la circulación y recepción de este tipo de escritos, ámbito sobre el cual existe todavía un importante vacío de conocimiento en la historiografía), el propósito de esta mirada panorámica es lisa y llanamente ponderar la relevancia de los textos con intención pedagógica y normalizadora sobre las costumbres infantiles y juveniles en el proceso de formación de la cultura impresa en Chile. Así, si atendemos a la doble dimensión del libro como cuerpo y alma, de acuerdo a Bernardo Subercaseaux, entendiendo que lo primero remite a las dimensiones materiales y económicas de los impresos y lo segundo a su papel de vehículo de pensamientos e ideas, podremos apreciar que los libros con propósito educacional nutrieron ambos aspectos, pero fueron singularmente importantes para que el primero de ellos tuviera viabilidad. De esta manera, los textos escolares ocuparon parte importante de los tirajes de la industria editorial chilena y fueron además un mercado atractivo, en la medida que el Estado desarrolló una política de entrega gratuita o a bajos precios de libros escolares, lo que implicó un importante poder comprador que ayudó a que la industria emergiera, aunque también fue eventualmente la fuente para que no pudiera expandirse o diversificarse a un ritmo distinto.

Un aspecto que merece ser tomado en cuenta al observar el desarrollo del conjunto de la literatura de orientación escolar en el Chile del siglo XIX es que durante la mayor parte del período predominaron traducciones o adaptaciones de textos extranjeros. En 
ese sentido, los textos pensados para la educación de niños y jóvenes chilenos fueron expresión, bajo filtros de estilo y selección de contenidos, tanto de tradiciones como de perspectivas de cambio que se originaban en la literatura europea, principalmente francesa. Las traducciones de textos tuvieron gran importancia en, a lo menos, dos sentidos: en lo que al alma del libro se refiere, significaron las primeras experiencias literarias de varios intelectuales nacionales, que bebieron doctrinalmente de las fuentes provenientes de la cultura francesa y, en segundo lugar, en lo que tiene que ver con la dimensión material, significaron un importante monto de ediciones. Como ejemplo, baste considerar que en el período 1865-69 se publicaron 112 libros en promedio al año, de los cuales 17 eran de temas religiosos y 95 correspondían a textos de estudio, obras y traducciones ${ }^{5}$.

Para la mayor parte del período que abordamos en estas páginas, este tipo de apropiación cultural mediante las traducciones de textos escolares y literarios da cuenta de la hegemonía cultural francesa como referente europeo para Chile. La presencia de educadores de esa nacionalidad, el modelo original inspirador de los primeros pasos del sistema educacional chileno, es trasunto de una comprensión predominante en los grupos dirigentes durante varias décadas del siglo XIX de la

"educación, como campo en permanente expansión, los libros, como componentes mediáticos de los saberes modernos, y la cultura francesa, como elemento codificador y contextualizador del nuevo universo simbólico civilizador, posibilitando y legitimando un verdadero y complejo proceso de transferencia cultural, cuyos alcances últimos son difíciles de precisar" ${ }^{\prime \prime}$.

A partir de la década de 1880 esa atracción incontestada sería desafiada y desplazada por las referencias a la pedagogía alemana, fruto de las reformas mayores a la educación chilena llevadas a cabo y simbolizadas en la fundación del Instituto Pedagógico (1889).

Con todo, no es posible hasta el momento precisar el peso específico de los textos de urbanidad al interior tanto de la literatura de orientación escolar como del conjunto de la producción impresa en el Chile del siglo XIX. Ello es así principalmente debido a dos circunstancias: la primera tiene que ver con la escasa información disponible respecto a los tirajes de cada edición de este tipo de textos y la segunda apunta a que esta área específica de estudio no tuvo espacio en el currículo como una asignatura identificable, razón por la cual no estuvo inscrita dentro de la oferta oficial de libros escolares, sobre la que sí es posible seguir una pista con mayor precisión.

Un segundo aspecto que merece ser considerado al observar los textos de urbanidad en el entorno de la cultura impresa chilena decimonónica tiene que ver con su formato. Con esto no apuntamos directamente a las dimensiones materiales de los textos (las que nos muestran una gran pluralidad, que va desde breves cartillas y

\footnotetext{
${ }^{5}$ Bernardo Subercaseaux, Historia del libro en Chile. Desde la Colonia hasta el Bicentenario, LOM, Santiago, 2010, pp. $84-85$.

${ }^{6}$ Juan Pablo Conejeros, La influencia cultural francesa en la educación chilena, 1840-1880, Ediciones Universidad Católica Cardenal Raúl Silva Henríquez, Santiago, 1999, p. 108.
} 
diminutos libros de bolsillo a manuales de gran cantidad de páginas), sino que a su naturaleza como vehículos de transmisión escrita de un saber. En este sentido es que es posible encontrar distintas denominaciones que se corresponden formalmente con intenciones diversas aunque estratégicamente comunes: cartillas, catecismos, compendios, manuales, textos todos en los que un factor común resulta ser el sentido normativo y la ausencia de elementos que involucraran algún tipo de actividad o reflexión de parte de los estudiantes. Ello no es de extrañar, si se considera el entorno de la literatura de intención educacional en América Latina durante buena parte del período de organización de los Estados Naciones, en que se puede notar la persistencia del estilo catequístico o apropiaciones de este porque "se adaptaba bastante bien a las condiciones de socialización política vigentes durante varias décadas en Latinoamérica"7.

\section{La enseñanza de la urbanidad, su lugar en el sistema de educación y el corpus de textos revisados.}

Desde las primeras organizaciones curriculares planteadas a inicios de la vida independiente, el campo específico de la urbanidad tuvo un sentido más bien complementario o transversal en la enseñanza, sin alcanzar un espacio por sí misma sino como compañera y subordinada de la educación moral y religiosa. Ello fue válido tanto para la enseñanza primaria como secundaria. En la educación dirigida a los sectores populares, sin embargo, puede notarse una más temprana y constante presencia de un núcleo curricular moralizador bajo el rótulo de Doctrina Cristiana. Para el caso español, a mediados del siglo XIX, los manuales de urbanidad dirigidos a la infancia popular cumplían la función de textos con los que se ejercitaba la lectura, por lo que satisfacían tanto una dimensión estrictamente cognitiva como una formativa ${ }^{8}$. En el sistema escolar peninsular y predominantemente bajo la forma de catecismos, los textos de urbanidad sirvieron como intermediarios culturales, con funciones domesticadoras y pensados para grupos específicos de la sociedad (mujeres, obreros), conforme avanzaba el siglo y con él la sensación de riesgo de polarización del conflicto social ${ }^{9}$. Sin embargo, esta persistencia de una catequística con impacto directo en el aula cuyo contenido específico era la urbanidad no es tan evidente en el caso de Chile, ya que no existió la asignatura como tal y sus contenidos centrales comenzaron a permear distintos ramos presentes en el currículo escolar, combinados con los comienzos de la instrucción cívica y la enseñanza de la higiene.

Pese a lo anterior, no fue escasa la presencia de textos dedicados principalmente a plantear los principios fundamentales de la urbanidad y dirigidos a la infancia y a los jóvenes. Usualmente la distinción para reconocer al destinatario de los textos estaba presente en sus títulos, salvo en escasos ejemplos en que los textos se consideraban como de aplicación universal. El término joven o la referencia a colegio señalaron cada

\footnotetext{
${ }^{7}$ Es lo señalado por Gabriela Ossenbach y Miguel Somoza en la introducción al libro del cual son editores, Los manuales escolares como fuente para la historia de la educación en América Latina, UNED Ediciones, Madrid, 2001, pp. 22 - 23.

${ }^{8}$ Jean-Louis Guereña, "El espacio de la urbanidad y del manual de urbanidad en el currículum", En Jean-Louis Guereña (director) Famille et education en Espagne et en Amerique Latine, Université de Tours, 2002, pp. 346 - 347.

${ }^{9}$ Manuel Morales Muñoz, "Civilismo y urbanidad en la catequística del siglo XIX", En Jean-Louis Guereña (director) Famille et education en Espagne et en Amerique Latine, Université de Tours, 2002, p. 343.
} 
vez con mayor precisión la segmentación del público que iba a ser normalizado, así como también los ejemplos o énfasis que se presentaban para entregar pautas de comportamiento apropiado.

A partir de lo recién indicado, hemos identificado un corpus de nueve textos explícitamente concebidos como manuales, compendios, catecismos o libros de consejo sobre urbanidad, que cubre un arco temporal que va desde 1847 a 1904, y que incluye referencias explícitas a jóvenes o $\operatorname{colegios}^{10}$. Es importante indicar que en algunos de ellos la urbanidad es concebida meramente como una acompañante de la enseñanza y la religión.

Para una lectura provechosa de los libros de cara a nuestro asunto, es necesario reforzar una precaución sobre la que ya se ha comentado algo, a propósito del impacto que los textos de esta área temática pudieron haber tenido en el conjunto de la literatura educativa de la época: la imposibilidad de determinar las cantidades en circulación. Desde la lógica de la demanda, una señal que algo podría indicar es que algunos de estos textos tuvieron varias ediciones. Así, por ejemplo, el manual de Lorenzo Robles de 1848 era ya la tercera edición del libro. Es plausible sostener, entonces, que existió una cierta regularidad en la oferta de textos pensados para la normalización de las maneras de la juventud y para ser usados en el ámbito escolar, paralelamente a un tipo de literatura que apoyaba este proceso, lo que hace pensar en una demanda que le dio sustento a través del tiempo. Testimonio de esa literatura de urbanidad sin destino explícitamente escolar podrían ser consideradas las publicaciones de libros de consejo como, por ejemplo, Las horas serias de un joven. Este texto, de clara orientación religiosa y que curiosamente tuvo dos ediciones distintas en un mismo año en nuestro país, reviste interés en la medida que releva tempranamente a la juventud como un actor privilegiado para la construcción del orden social, ya que el joven es

"fuerte con toda la experiencia que le han legado los siglos pasados; poderoso, con todos los medios que el presente pone a su disposición; rico con todas las esperanzas que le da el porvenir"11.

\footnotetext{
${ }^{10}$ En orden cronológico, son:

Philip Chesterfield, Preceptos de urbanidad y buena crianza, o reglas para comportarse con lucimiento en la Sociedad. Estracto de las cartas de Lord Chesterfield a su hijo Felipe Stanhope; testo en inglés con la traducción española al fuente, Imprenta del Mercurio, Valparaíso, 1847.

Manual de moral, virtud i urbanidad: dispuesto para jóvenes de ambos sexos /por el Presbítero D. Lorenzo Robles, Imprenta Chilena, Santiago, 1848.

José María Mestre y Marzal, Consejos morales a la niñez, seguido de las reglas de urbanidad puestos en verso /por Carlos Mestre i Marzal, Imprenta Chilena, Santiago, 1849.

Compendio de reglas de urbanidad para el uso de los colegios y útil a toda clase de personas. Imprenta de la Opinión, Santiago, [mayo] 1857.

Compendio de reglas de urbanidad para el uso de los colegios de la capital,Imprenta Nacional, Santiago, 1860.

El niño instruido en relijión, moral i urbanidad: precioso librito, destinado a la lectura de los niños en las Escuelas i en las Bibliotecas populares aprobado...y arreglado por Manuel José Zapata, Imprenta Chilena, Santiago, 1863.

Manual de urbanidad para uso de los colegios. Arreglado por un profesor del Seminario de Santiago, Imprenta Cervantes, Santiago, 1893.

Manual de urbanidad para uso de los colegios, Escuela S. Vicente de Paul, Valparaíso, 1898.

Arturo L. Constancin, Manual de urbanidad é higiene: para colegios de externos, Litografía e Imprenta Sud-americana Babra, Valparaíso, 1904.

${ }^{11}$ Charles Sainte-Foix, Las horas serias de un joven, Imprenta del Progreso, Santiago, 1843, p. 13.
} 
Complementariamente, la aparición de traducciones de textos de etiqueta o reflexiones sobre el buen comportamiento y las virtudes estéticas asociadas a la concepción burguesa y cosmopolita de elegancia, antes de la circulación masiva del célebre Manual de Carreño desde 1853 también forma parte de este tipo de textos de lectura general ${ }^{12}$.

Teniendo a la vista lo anterior, cabe señalar que la difusión de los textos es un proceso que cobra significado pleno cuando es posible perfilar con claridad su utilización efectiva, asunto tanto más relevante en lo que a manuales orientadores de la conducta juvenil se refiere. En virtud de ello es que un análisis suficientemente cauto de los textos debiera observar lo limitadas que son, en general, las posibilidades de emplear los manuales como fuente en lo que se refiere a su uso en el aula y a la apropiación que los sujetos involucrados hacen de sus contenidos si no se recurre a fuentes complementarias que den testimonio de los actores ${ }^{13}$. Esta dificultad, para el caso que abordamos, si bien no es totalmente salvada al menos es levemente aminorada, en la medida que para caracterizar el campo específico de la formación de la urbanidad en la juventud presentamos a continuación una selección de aspectos de contenidos presentes en el corpus analizado, los que son combinados con referencias a prácticas de docentes que buscaban integrar los valores de la urbanidad, forma propiciatoria (e indispensable) para la emergencia de la civilidad entendida como conjunto de conductas organizacionales motivadas conscientemente, en que los individuos participan en las instituciones y formas de convivencia social creadas por la colectividad con el propósito de hacerlas perdurar y perfeccionarse, propósito para el cual las formas de trato, la etiqueta y la conducta bajo patrones de jerarquía reconocibles, objetos propios de la urbanidad, eran de gran importancia ${ }^{14}$.

\section{La urbanidad en la letra y la acción: manuales y profesores}

Los textos que hemos consultado presentan rasgos estereotipados, en que sus estructuras suelen ser muy semejantes, así como también los dominios sobre los cuales reconocen que es necesario establecer discursos de normalización para la juventud. En la medida que son traducciones o adaptaciones de manuales extranjeros, acostumbran tener una breve introducción en la que se presenta una definición de qué se entiende por urbanidad, concepto que suele no tener divergencias radicales entre autores y textos a través del período analizado. Un texto de 1848 la concibe como

"el arte de ordenar agradablemente nuestras acciones y palabras, atendiendo al lugar en que nos encontramos y a la edad, condición y sexo de las personas que están con nosotros"15.

\footnotetext{
${ }^{12}$ Es lo que informa sobre el libro de Sainte-Foix José Toribio Medina en su Biblioteca chilena de traductores. Imprenta y Litografía Universo, Santiago, 1925, p.25. Los dos traductores son Juan Bello (en la edición de Santiago) y Eugenio de Ochoa (en Valparaíso). En 1849 se da a luz una edición local del libro de Eugenio Chapus Teoría de la elegancia. Traducida del francés por J.N. Villegas (Agencia del Mercurio, Santiago, 1849).

${ }^{13}$ Chloé Schurdevin-Blaise, "Los manuales escolares como fuente de la historia chilena (1850-1860): aportes y limitaciones". En Boletín Americanista, Año LVII, n57, 2007, pp. 270 - 271.

${ }^{14}$ Una perspectiva panorámica sobre el concepto se encuentra en el estudio de Dennis L. Peck "Civility: a contemporary context for a meaningful historical concept", en Sociological Inquiry, v.72, n 3, summer 2002, pp. 358 - 375.

${ }^{15}$ Manual de moral, virtud y urbanidad. Dispuesto para los alumnos del Liceo por su director el presbítero D. Francisco de Paula Taforó, Imprenta Chilena, Santiago, 1848, p.7.
} 
Este sentido de acomodo de la conducta de acuerdo al estatus del interlocutor es interesante como mensaje, en la medida que involucra una propedéutica para el reconocimiento de las diferencias en una sociedad que, con todo, tiene una base discursiva que se halla eliminando, con velocidad e intensidad irregulares, signos institucionales que avalan la diferencia propia de órdenes estamentales rígidos para introducir otros códigos de distinción.

Por otra parte, un tópico que es frecuente en los textos revisados es la idea de que la urbanidad corresponde a un atributo integral que los jóvenes deben internalizar debido a que no reconoce límites entre lo privado y lo público. De esta manera, "el modo de ser urbano es serlo siempre con todos y en todas partes. No se puede ser grosero $u$ ordinario en la casa y educado y fino a ciertas horas en la sociedad"16. El amplio conjunto de normas contenidas en el código de conducta de una persona urbana y política (pues todavía se emplea el término, más bien propio de décadas anteriores), se entiende como una segunda naturaleza, un hábito del cual es imposible despojarse y que involucra beneficios instrumentales como "granjearnos con nuestros modales la estimación de los demás"17.

Otro elemento que es interesante considerar es que en los textos el sustento que brinda sentido a las formas involucradas en la urbanidad presenta un doble rostro: por una parte, se aprecia una cara de continuidad, asociada con la tradición cristiana, y por otro una apuesta a la adaptación a valores seculares, vinculada con lo cosmopolita y la adscripción a una idea de civilización que tendría parámetros basados en un imaginario burgués. En el primer sentido, por ejemplo, un texto sostiene que "con la misma caridad cristiana se hermana en mucho la urbanidad, pues ésta, en cuanto a los demás se refiere, nos hace considerarlos como semejantes"18. La conducta social, por tanto, es una extensión de la filiación cristiana y un deber para con el otro. Sin encontrarse necesariamente en sus antípodas, otros textos suelen enfatizar el sentido civil o de beneficio social al cual sirve la urbanidad. Ilustrativo de ello es, por ejemplo, esta parte de un "alfabeto moral" para guiar la conducta de los estudiantes:

$$
\begin{aligned}
& \text { "Sociedad es el Estado } \\
& \text { En que con otros vivieres } \\
& \text { Y serás social si fueres } \\
& \text { Justo, modesto y aseado"19. }
\end{aligned}
$$

El fundamento social o utilitario de la urbanidad no entra necesariamente en polémica con las consideraciones religiosas. Podría sostenerse, sin embargo, que las soslaya en cuanto enfatiza las dimensiones instrumentales del buen comportamiento social para el beneficio individual. Asuntos tan relevantes a la etapa juvenil (tal cual se la concibe en el mundo moderno) como la amistad, por ejemplo, son tematizados desde

\footnotetext{
${ }^{16}$ Manual de urbanidad para uso de los colegios. Arreglado por un profesor del Seminario de Santiago. Imprenta Cervantes, Santiago, 1893, p.4.

${ }^{17}$ Compendio de reglas de urbanidad para el uso de los colegios de la capital, Imprenta Nacional, Santiago, 1860, p.3.

${ }^{18}$ Manual de urbanidad para uso de los colegios. Arreglado por un profesor del Seminario de Santiago, Imprenta Cervantes, Santiago, 1893, p.5.

${ }^{19}$ El niño instruido en relijión, moral i urbanidad: precioso librito, destinado a la lectura de los niños en las Escuelas i en las Bibliotecas populares aprobado...y arreglado por Manuel José Zapata, Imprenta Chilena, Santiago, 1863, p.98.
} 
el consejo sobre los comportamientos y la sociabilidad que los jóvenes han de cultivar. Un texto sostiene admonitoriamente al respecto que "las gentes por lo general, y con mucha razón, se formarán de ti una opinión, conforme a la que tuvieren de tus amigos $^{\prime 20}$.

Ahora bien, tanto las concepciones sobre lo que es propiamente urbanidad así como los códigos conductuales asociados a ella, detalladísimos en enumeraciones casuísticas tal como pueden ser vistas en catecismos y manuales, son orientaciones a priori que podríamos entender como principalmente prescriptivas y que no se basan en respuestas frente a la praxis de jóvenes y niños. Considerar la posibilidad de entender al proceso de difusión de la urbanidad en el sistema educacional como parte de la confección de una juventud, del modo que hemos señalado anteriormente, requiere que junto con pensar en la lógica de un molde (el cual serían precisamente estos preceptos de sentido general) también se considere el cuerpo (vale decir, las conductas y características de los sujetos involucrados). En este sentido es que surge la necesidad de observar a la urbanidad como reacción, como herramienta frente a las conductas o carencias que se les atribuye a los jóvenes como parte de su índole.

De esta manera es que se hace comprensible que la urbanidad se haya convertido en una necesidad detectada para la formación de la juventud, de acuerdo a algunos docentes que, tras ese diagnóstico, implementaron acciones tanto a través de la prensa, los textos de estudio, como en su mismo entorno de desempeño. Una lectura de la urbanidad como remedio y prevención frente a la emancipación conductual de los muchachos, en tanto se reconocían progresivamente como iguales y realizaban acciones que involucraban ruptura de las jerarquías, comenzó a emerger ya hacia fines del período en estudio. Así, un autor se quejaba amargamente de que

"una juventud dorada ${ }^{21}$ que ha aparecido en Santiago, de poco tiempo a esta parte, y que se burla, en la calle pública, de señoras respetables, nos está probando que hemos descuidado lastimosamente estas enseñanzas, tanto en el hogar como en los colegios y escuelas" ${ }^{\prime \prime 2}$.

Por otra parte, una profesora señalaba las preocupantes conductas de

“(...) jóvenes que salen de las aulas de establecimiento superiores ofendiendo con sus dichos importunos el candor de la inocente niña: en las reuniones de sociedad oímos muchas veces a los niños y niñas dejar avergonzados a sus padres interrumpiéndoles importunamente sus conversaciones; en una palabra, todos éstos demuestran a las claras que poco o nada han aprovechado de las lecciones de moral y urbanidad"23.

En ambos casos se coincidía en las deficiencias de la respuesta formativa tanto escolar como doméstica frente al desenfado juvenil, lo que servía como argumento para

\footnotetext{
${ }^{20}$ Philip Chesterfield, Preceptos de urbanidad y buena crianza, o reglas para comportarse con lucimiento en la Sociedad. Estracto de las cartas de Lord Chesterfield a su hijo Felipe Stanhope; testo en inglés con la traducción española al fuente, Imprenta del Mercurio, Valparaíso, 1847, p.28.

${ }^{21}$ Cursiva en el original

22 José Bernardo Suárez, Compendio de moral i urbanidad, arreglado para uso de las escuelas primarias, Imprenta de Los Tiempos, Talca, 1890, p.5.

${ }^{23}$ Enriqueta Courbis, "Urbanidad y moral" en El Educador, periódico quincenal, 1890. N9, 1 de noviembre de 1890.
} 
fundamentar la necesidad de la enseñanza de la urbanidad.

Las conductas juveniles disfuncionales debían, pues, ser combatidas por la promoción de los códigos de la urbanidad. Si, como se ha indicado, ésta era comprendida como un hábito que acompañaba al individuo en las distintas esferas en que se encontrara, era necesaria entonces la sinergia entre escolaridad y familia. Sin embargo, el diagnóstico de un autor de textos de urbanidad no era nada alentador pues detectaba que

"en el Instituto Nacional y liceos provinciales los rectores y profesores se limitan exclusivamente a la enseñanza de las ciencias y dejan la moral y la urbanidad al cuidado de los padres de familia que, por lo general, no son más instruidos que los hijos"24.

Una opinión tan crítica como la de José Bernardo Suárez era la del rector de un liceo de provincia que, sin embargo, reivindicaba los esfuerzos llevados a cabo

"para contrarrestar las influencias domésticas de unos y corregir una educación mal dirigida de otros", en que él mismo daba todos los sábados una clase "con algunas nociones de civismo, urbanidad y buen comportamiento. En las atenciones que demandan este servicio me secundan dignamente los inspectores del Liceo, quienes están así mismo muy penetrados de que la disciplina de la conducta es tan importante como la del espíritu $(\ldots)^{\prime \prime 25}$.

La percepción respecto a que la difusión de los códigos propios de la urbanidad no estaba teniendo éxito es un fenómeno que comienza a cobrar mayor importancia hacia los tramos finales de nuestro período de estudio, lo que resulta consistente con una renovada preocupación por las conductas de los colegiales, sobre todo en el espacio público.

El riesgo de ruptura de la relación jerárquica entre adultos y jóvenes (entendidos como estudiantes) en el ámbito urbano era una de las preocupaciones más importantes para promover códigos de comportamiento apropiado. Ciertas continuidades en un proceso de normalización de amplio espectro temporal podían apreciarse al encontrar la persistencia de tópicos como la regulación corporal de los jóvenes en su tránsito por las calles. Prescribía un Manual en 1893 que

“el colegial bien criado se conducirá en la calle con toda modestia y circunspección y no debe llevar la vista pendiente de todo lo que pasa, las manos deben ir naturalmente caídas y jamás en los bolsillos del pantalón ni tampoco les imprimirá un movimiento horizontal. Escusado es decir que es evidente señal de mala crianza el ir silbando y cantando por la calle"26.

Un poco más de un siglo antes, de acuerdo a las constituciones del Convictorio Carolino, intenciones semejantes se depositaban en que los estudiantes fueran

\footnotetext{
${ }^{24}$ José Bernardo Suárez, Compendio de moral i urbanidad, arreglado para uso de las escuelas primarias, Imprenta de Los Tiempos, Talca, 1890 , p. 5

${ }^{25}$ Archivo del Liceo de Curicó, Libro Copiador de Oficios (1867-1898), Carta del 30 de abril de 1889.

${ }^{26}$ Manual de urbanidad para uso de los colegios. Arreglado por un profesor del Seminario de Santiago, Imprenta Cervantes, Santiago, 1893, p.50.
} 
"por la calle con gravedad cristiana, modestos, sin bracear ni rebosarse, ajustados en las palabras y en las demás acciones para que causen estimación y edifiquen a los que los miren"27.

Junto con la denuncia del peligro de las conductas desviadas, las acciones adultas con respecto a la promoción de la urbanidad en los jóvenes estudiantes en el ámbito escolar también se plantearon desde las necesidades y carencias que creían detectar en los muchachos. Más allá del sentido prescriptivo que buena parte de los códigos contenidos en los manuales involucraba, con su densa red de prohibiciones y mandatos, la urbanidad también contenía un campo de acción que enriquecería a los sujetos en formación de cara a sus desempeños futuros en la vida adulta. Así, la promoción de una etiqueta de contenidos universalistas recalaba, a través de sus intérpretes adultos, en la formación de las juventudes de provincia. Manuel Antonio Carmona, rector del Liceo de San Felipe (1843-1845) "frecuentemente asistía a la comida de los internos, aprovechando la oportunidad que se le ofrecía para disertar sobre los modales de la gente educada y corregir cualquier acto inconveniente o grosero de los que inconscientemente suelen ejecutar los niños en la mesa", pero no limitaba su prédica de la etiqueta a esto sino que "quiso tocar todos los recursos encaminados a formar de sus alumnos personas educadas, en el más amplio sentido. Con este fin, estableció una clase de baile al que concurrían veinticinco alumnos de los mayores y más aprovechados", los que tenían permitido retornar más tarde al Liceo, para poder "practicar el baile en las casas de respeto de la ciudad, a que concurrían de visita" ${ }^{\prime \prime 2}$.

Modales finos, dominio de habilidades para la socialización en contextos exigentes en la performance de la distinción, eran recursos que un rector de liceo de provincia consideraba que constituirían un capital para sus jóvenes estudiantes.

Por su parte, años después y cientos de kilómetros al norte, Rafael Minvielle, rector del Liceo de La Serena, informaba en abril de 1884 de su iniciativa personal de intentar revertir el mal manejo de lenguaje y maneras de sus estudiantes, para lo cual pretendía "en parte remediar este mal abriendo semanalmente una clase de urbanidad, que empezará a funcionar el sábado 19 del corriente y que haré yo"29. Años antes, durante el decenio en que fue alumno del plantel serenense (1862-1872), el joven Bernardo Ossandón asistió a las conferencias que el profesor Francisco Ángel Ramírez les daba a los alumnos internos sobre "diversos temas morales, de cultura social y buenos modales y sobre formación del carácter" ${ }^{\prime \prime 30}$.

\section{Reflexiones finales}

La promoción de códigos de urbanidad en la juventud escolarizada, vistos como guías orientadoras de sus conductas privadas y públicas, tuvo lugar mediante manuales y la

\footnotetext{
${ }^{27}$ Las Constituciones de 1772 aparecen transcritas como anexo documental en el libro de José Manuel Frontaura, Historia del Convictorio Carolino, Imprenta Nacional, Santiago, 1889.

${ }^{28}$ Roberto Humeres, Historia del Liceo de San Felipe, Imprenta Cervantes, Santiago, 1907, p.34.

${ }^{29}$ Memoria del Ministerio de Justicia, Culto e Instrucción Pública, Establecimiento Poligráfico Roma, Santiago, 1884 , p.75.

${ }^{30}$ Bernardo Ossandón, "Liceo de La Serena. Recuerdos de un ex alumno. Decenio 1862-1872", en Revista Chilena de Historia y Geografía, n 42, 1921, p. 395.
} 
acción de docentes, entre otros medios. Ciertamente, este esfuerzo de normalización en el Chile de la segunda parte del siglo XIX afectó a un grupo numéricamente selecto respecto a su cohorte etaria a lo largo del período en estudio, lo que resulta congruente con la perspectiva historiográfica que sostiene que el proceso de definición de la juventud como un actor reconocido desde afuera y asignado de identidad desde sí mismo encontró en la escolarización una de sus fuerzas coadyuvantes. A través de estas páginas se ha constatado que las necesidades estratégicas relacionadas con el gobierno adulto sobre los jóvenes, asunto que cobró sentido cada vez más urgente hacia finales del período en estudio, generó un espacio de demanda para la difusión de la urbanidad, pese a que no tuviera un correlato curricular explícito en la educación que se les brindaba. Valores con referencia a una visión de cristiandad u orientados por un horizonte secular encontraron en la construcción de preceptos conductuales (aplicables universalmente y en todo espacio) una forma de expresión apropiada, aunque no necesariamente suficiente, para las necesidades de control de la juventud que se percibían como indispensables en una sociedad que, al menos discursivamente desde un ánimo republicano, sostenía la abolición de privilegios con base en la tradición y fortalecía la adhesión a un imaginario europeizante.

\section{Fuentes y Bibliografía}

Fuentes

Archivo del Liceo de Curicó, Libro Copiador de Oficios (1867-1898).

Compendio de reglas de urbanidad para el uso de los colegios y útil a toda clase de personas, Imprenta de la Opinión, Santiago, [mayo],1857.

Constancin, L. A., Manual de urbanidad é higiene: para colegios de externos, Litografía e Imprenta Sud-americana Babra, Valparaíso, 1904.

Chesterfield, P., Preceptos de urbanidad y buena crianza, o reglas para comportarse con lucimiento en la Sociedad. Estracto de las cartas de Lord Chesterfield a su hijo Felipe Stanhope; testo en inglés con la traducción española al fuente, Imprenta del Mercurio, Valparaíso, 1847.

Manual de moral, virtud y urbanidad. Dispuesto para los alumnos del Liceo por su director el presbítero D. Francisco de Paula Taforó, Imprenta Chilena, Santiago, 1848.

Manual de urbanidad para uso de los colegios, Escuela S. Vicente de Paul, Valparaíso, 1898.

Memoria del Ministerio de Justicia, Culto e Instrucción Pública, Establecimiento Poligráfico Roma, Santiago, 1884.

Mestre y Marzal, J. M., Consejos morales a la niñez, seguido de las reglas de urbanidad puestos en verso, Imprenta Chilena, Santiago, 1849. 
Sainte-Foix, C., Las horas serias de un joven, Imprenta del Progreso, Santiago, 1843.

Suárez, J. B., Compendio de moral i urbanidad, arreglado para uso de las escuelas primarias, Imprenta de Los Tiempos, Talca, 1890.

\section{Libros y artículos}

Conejeros, J. P., La influencia cultural francesa en la educación chilena, 1840-1880, Ediciones Universidad Católica Cardenal Raúl Silva Henríquez, Santiago, 1999.

Courbis, E., "Urbanidad y moral" en El Educador, periódico quincenal, N9, 1 de noviembre de 1890.

Frontaura, J. M., Historia del Convictorio Carolino, Imprenta Nacional, Santiago, 1889.

Guereña, J. L., "El espacio de la urbanidad y del manual de urbanidad en el currículum". En Jean- Louis Guereña (director) Famille et education en Espagne et en Amerique Latine, Université de Tours, 2002, pp. 345 - 357.

Hessinger, R., Seduced, abandoned and reborn. Visions of Youth in middle-class America, 1780 - 1850, University of Pennsylvania Press, Philadelphia, 2005.

Humeres, R., Historia del Liceo de San Felipe, Imprenta Cervantes, Santiago, 1907.

Labarca, A., Historia de la enseñanza en Chile, Ediciones Universidad de Chile, Santiago, 1939.

Medina, J. T., Biblioteca chilena de traductores, Imprenta y Litografía Universo, Santiago, 1925.

Morales Muñoz, M., “Civilismo y urbanidad en la catequística del siglo XIX”. En JeanLouis Guereña (director) Famille et education en Espagne et en Amerique Latine, Université de Tours, 2002, pp. 335 - 344.

Ossandón, B., “Liceo de La Serena. Recuerdos de un ex alumno. Decenio 1862-1872", en Revista Chilena de Historia y Geografía, n 42, 1921.

Ossenbach, G. y Somoza, M., (editores) Los manuales escolares como fuente para la historia de la educación en América Latina, UNED Ediciones, Madrid, 2001.

Peck, D., "Civility: a contemporary context for a meaningful historical concept", en Sociological Inquiry, V. 72, nº 3, summer 2002, pp. 358 - 375. 
Schurdevin-Blaise, C., "Los manuales escolares como fuente de la historia chilena (1850-1860): aportes y limitaciones", en Boletín Americanista, Año LVII, n57, 2007, pp. $257-272$.

Souto Kustrin, S., "Introducción: juventud e historia", en Hispania. Revista Española de Historia, 2007, Vol. LXVII, núm. 225, enero-abril, pp. 11 - 20.

Subercaseaux, B., Historia del libro en Chile. Desde la Colonia hasta el Bicentenario, LOM, Santiago, 2010.

Toro Blanco, P., La letra ¿con sangre entra? Percepciones, normativas y prácticas de disciplinas, castigos y violencias en el liceo chileno, c.1842-c.1912, Comisión Bicentenario [Concurso Bicentenario Tesis Doctoral 2007, volumen II], Santiago, 2009. 